\title{
Shallow-water, Coral Reef and Mangrove Amphipoda (Gammaridea) of Fiji
}

\author{
A.A. Myers \\ Department of Zoology, University College, \\ Cork, Ireland
}

\begin{abstract}
Eighty species of marine gammaridean Amphipoda are currently known from Fiji. During a three month period in late 1979, 77 species were collected, and these are described and figured. Keys for the identification of all known Fijian species are included.

Fiji appears to share most of its taxa with Hawaii, Indonesia and the Indian Ocean, and few with eastern Polynesia, but this may reflect collecting intensity. Few taxa are shared with New Zealand. Forty percent of Fijian taxa are new to science. Forty-one percent of taxa are currently of endemic status but this figure will undoubtedly be lowered when more Indo-Pacific island groups are explored. Fiji is characterised by a higher percentage of domicolo!ns forms than any other well studied island group. The results of a quantitative survey of amphipods on a transect across a fringing reef in south Viti Levu are given.
\end{abstract}

MyERS, A.A., 1985. Shallow-water, coral reef and mangrove Amphipoda (Gammaridea) of Fiji. Records of the Australian Museum Supplement 5: 1-143.

KEywords: Amphipoda, marine, taxonomy, Fiji.

\section{CONTENTS}

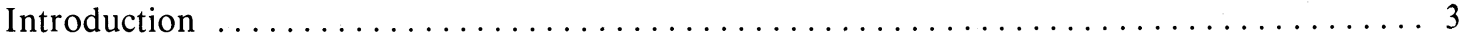

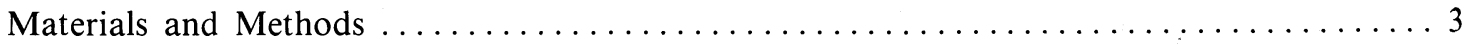

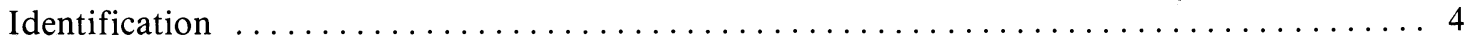

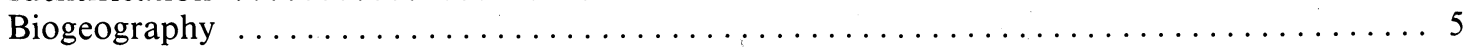

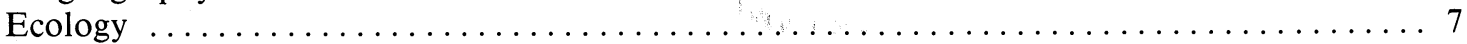

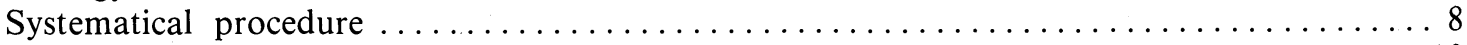

Key to families of Fijian Gammaridea $\ldots \ldots \ldots \ldots \ldots \ldots \ldots \ldots \ldots \ldots \ldots \ldots \ldots \ldots \ldots$

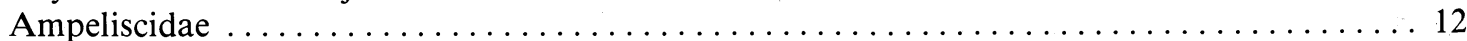

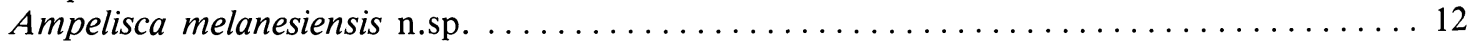

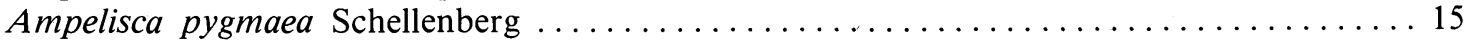

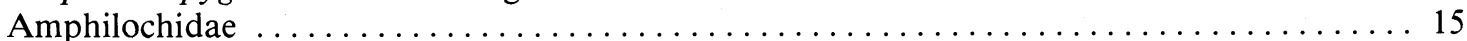

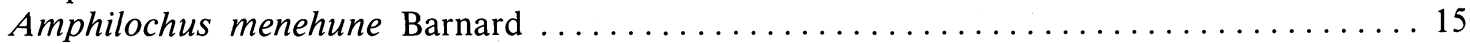

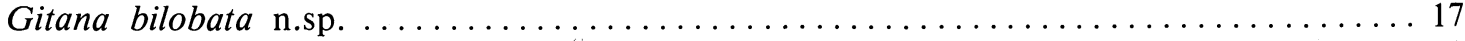

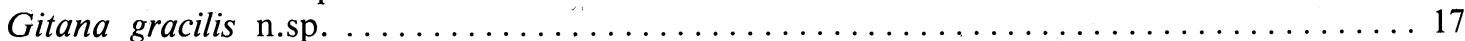

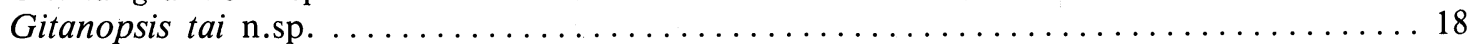

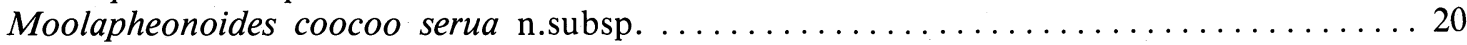

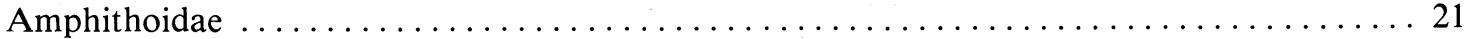

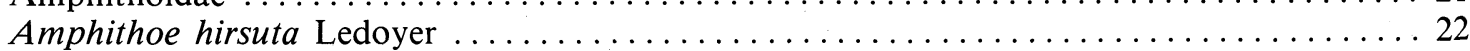

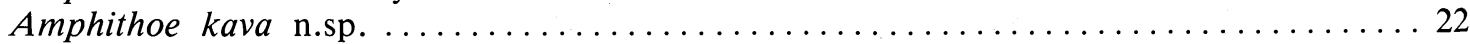

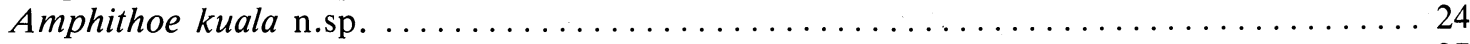

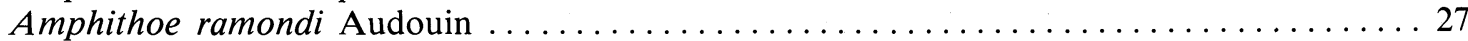

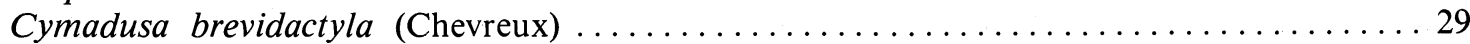

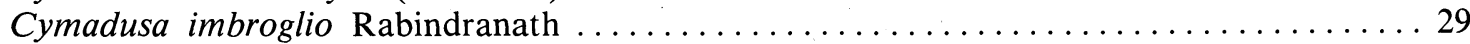

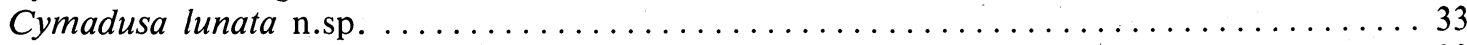

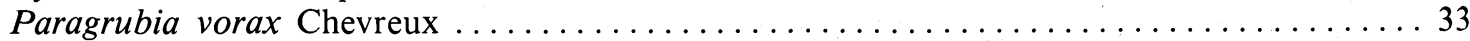

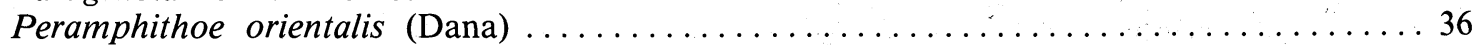

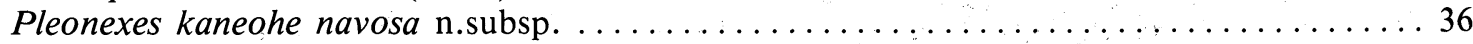


Pleonexes kulafi (Barnard) ................................ 40

Anamixidae ......................................... 42

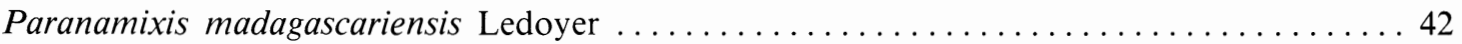

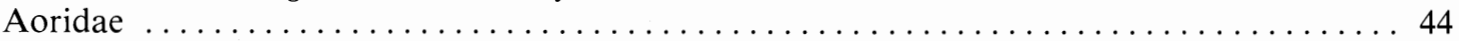

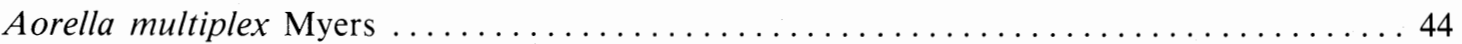

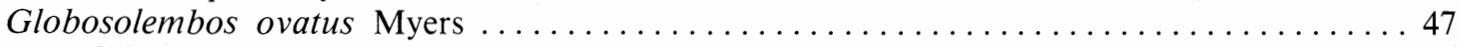

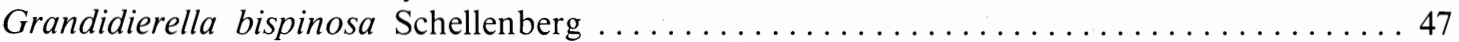

Grandidierella perlata Schellenberg ..............................49

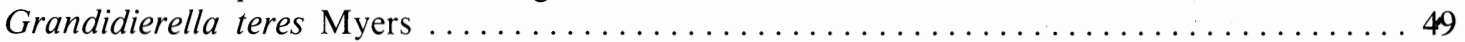

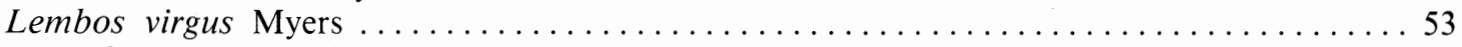

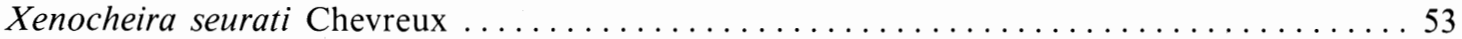

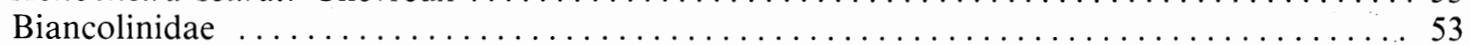

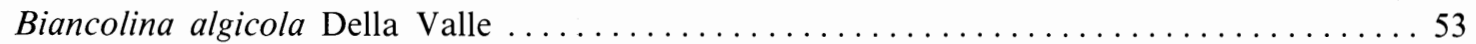

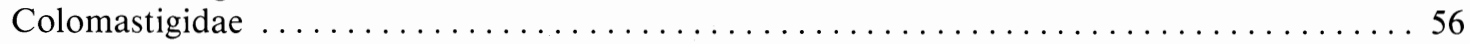

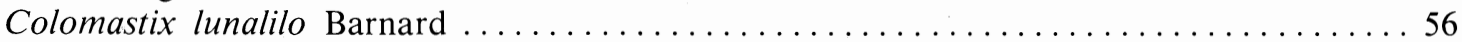

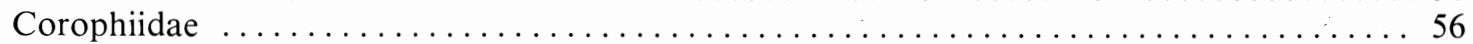

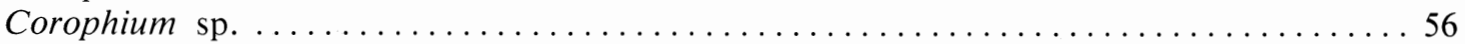

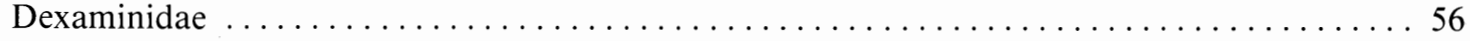

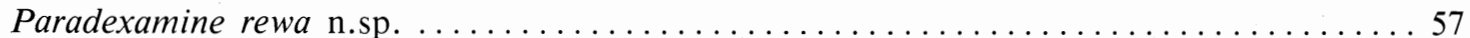

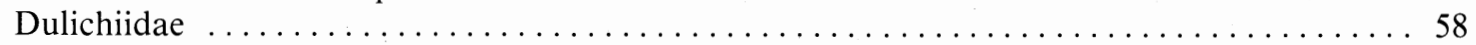

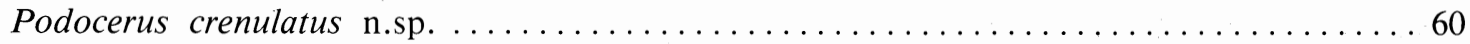

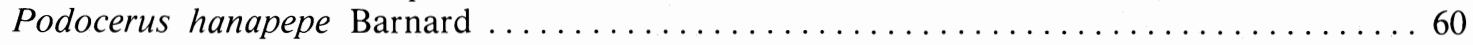

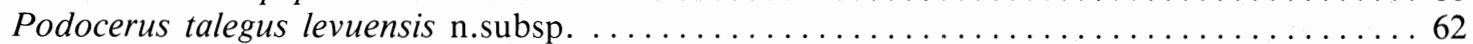

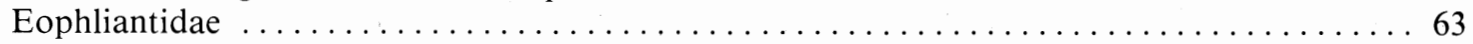

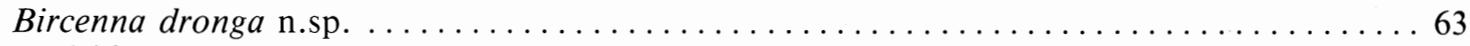

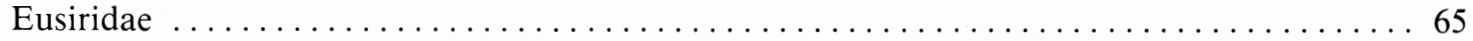

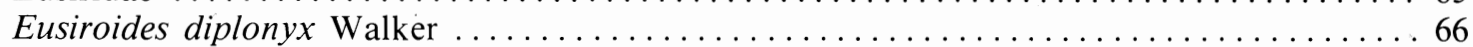

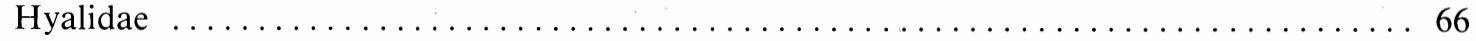

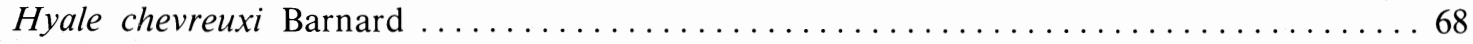

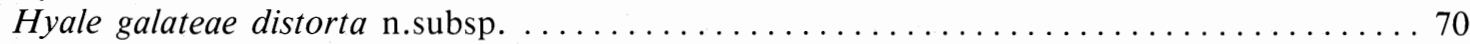

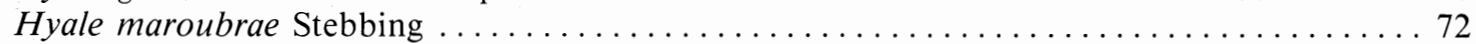

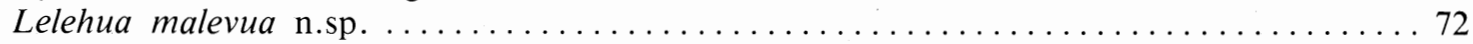

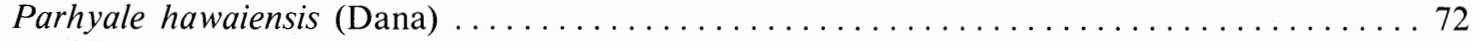

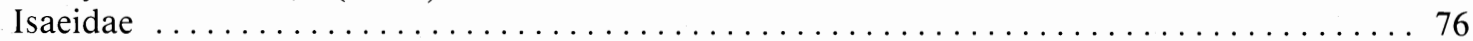

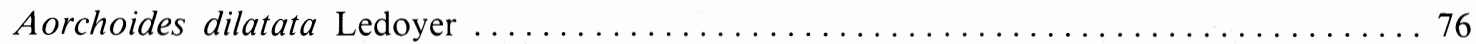

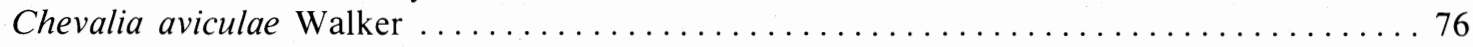

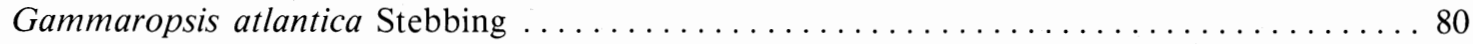

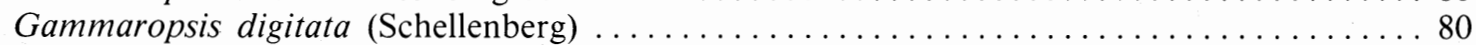

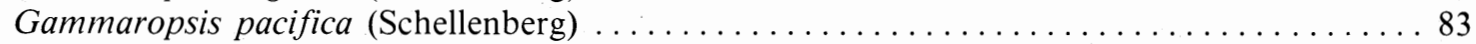

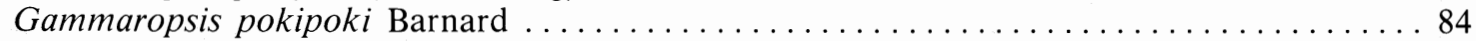

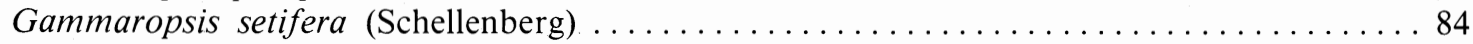

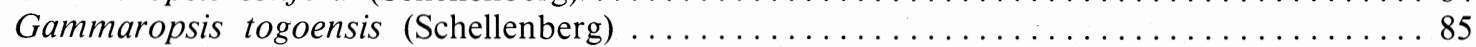

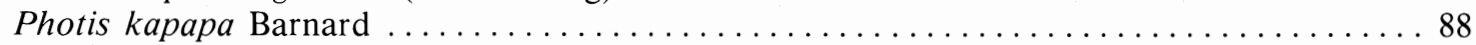

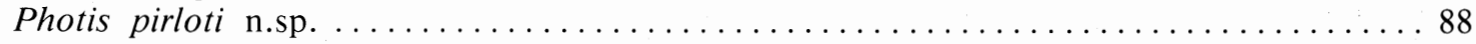

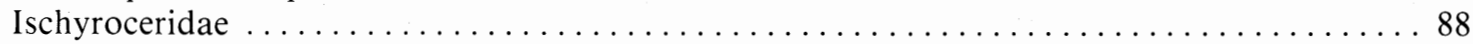

Cerapus pacificus Lowry ..................................... 89

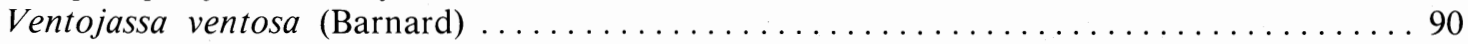

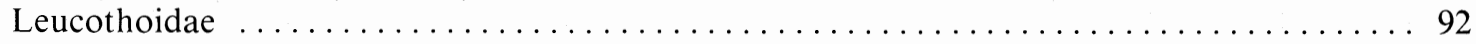

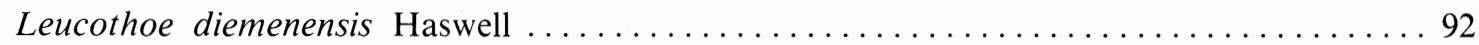

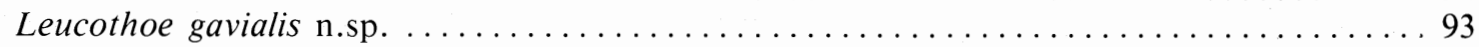

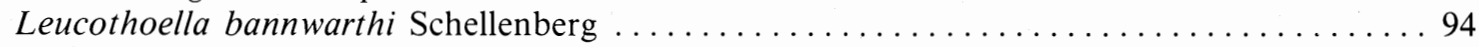

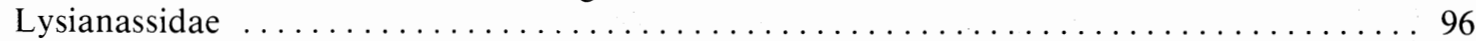

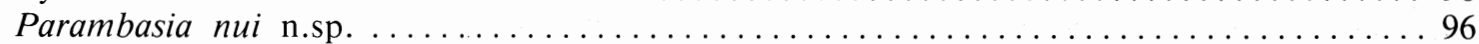

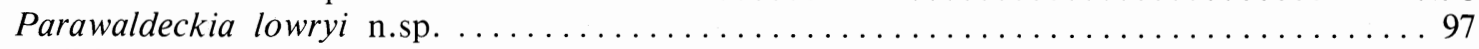

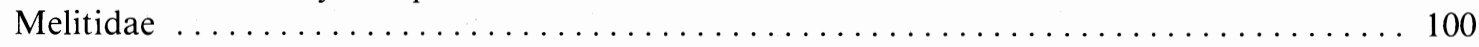

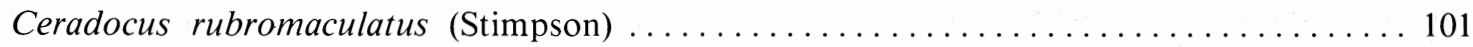

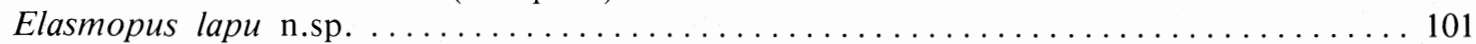

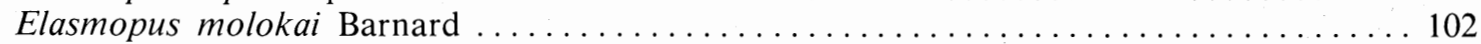

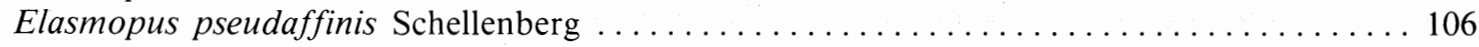

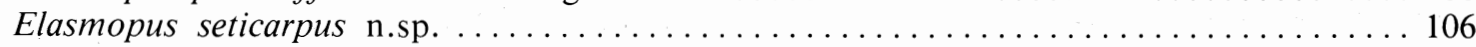




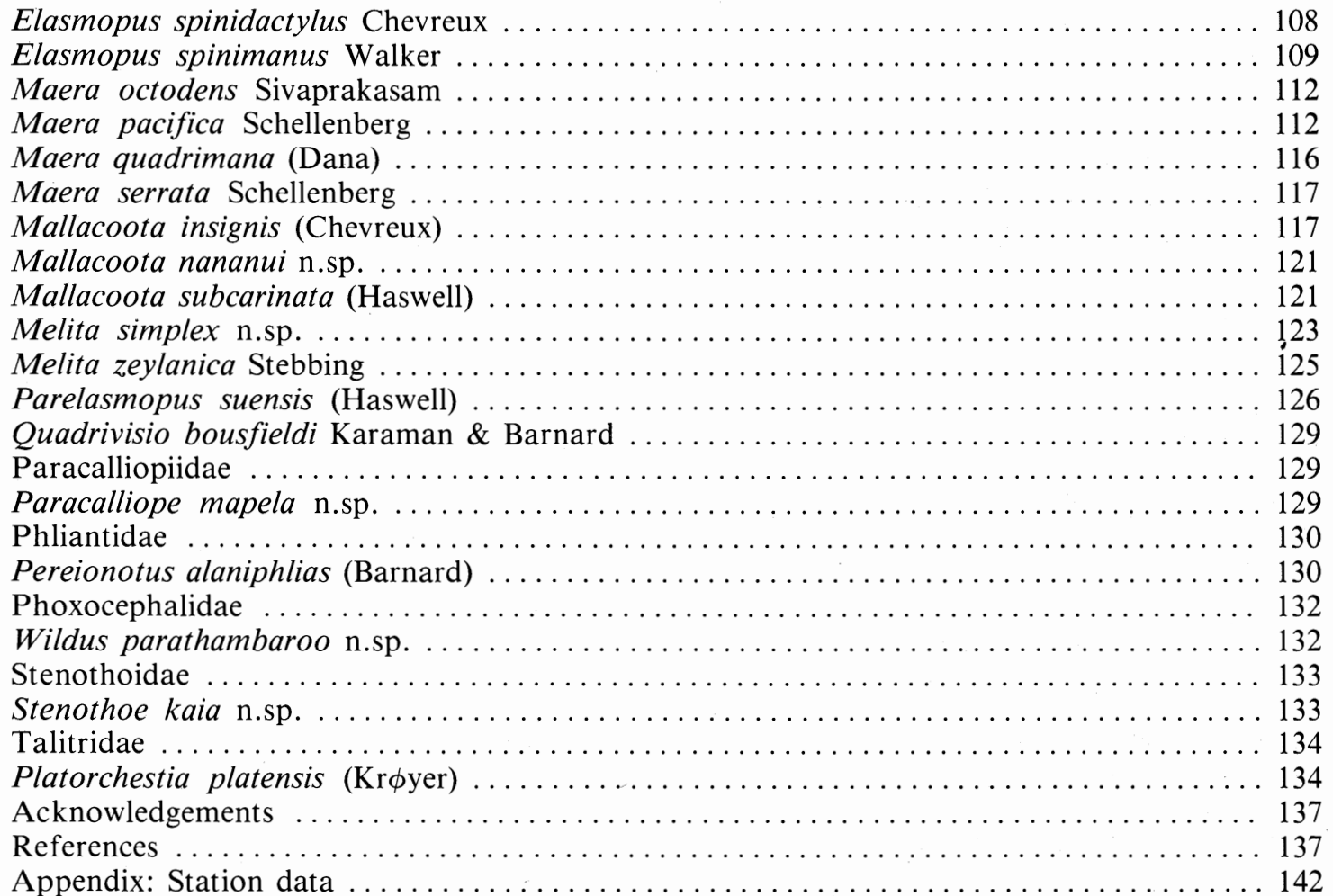

Taxonomic literature on the gammaridean amphipods of Central Pacific tropics is sparse, as indeed it is for the entire Indo-Pacific tropics (see review by Barnard, 1976). The most comprehensive studies of Pacific amphipods are those of Barnard (1955, 1970 and 1971) from Hawaii, but other important works are those of Chevreux (1908) from French Polynesia, Barnard (1965) from Micronesia, and Dana (1853) and Schellenberg (1938) from a wide range of Pacific localities. The only records of marine amphipods from the Fijian islands are those of Dana (1853) who recorded three species, two of which, Gammarus fuegiensis and G. tenellus, are too poorly described to be referred to any known species, and Schellenberg (1938) who recorded 17 species, four of which (Elasmopus dentiferus Schellenberg, E. gracilis Schellenberg, E. rapax Costa and Lembos aequimanus Schellenberg) remain doubtful records.*

With the establishment of the University of the South Pacific on Viti Levu, Fiji, and in particular, the University Department of Marine Resources, increasing ecological works on the coral reefs and mangroves of the region are to be expected. Such works cannot successfully be carried out until knowledge of the fauna is given a sound taxonomic basis. The present work is

\footnotetext{
* Elasmopus gracilis and L. aequimanus were represented only by females from Fiji. Elasmopus dentiferus was described and figured by Schellenberg from Kiribati and, in the light of the high diversity of this genus in the tropics, the Fijian record requires confirmation. Elasmopus rapax is taxonomically problematical; Schellenberg's material may be referable to E. molokai Barnard.
}

intended to provide a guide to the gammaridean amphipods of Fijian coral reefs and mangroves. The material upon which this work is based was collected during a three month period from August to October 1979. Further collecting would undoubtedly result in the discovery of additional species, particularly those living in specialised habitats. Such collecting would, however, bring diminishing returns, and the present guide should form a practical basis for the identification of at least most of the commonly encountered species, and hopefully encourage work on this important group of marine organisms which contribute to many coral reef and mangrove energy budgets. Whilst collecting was restricted to Viti Levu in the Fijian archipelago, the guide should prove generally applicable throughout the Fijian islands and near Pacific islands.

\section{Materials and Methods}

Samples of algae, corals, coral rocks, coral debris, sponges, zoanthids etc. were obtained by wading or snorkling in shallow water. Samples were placed in buckets containing sea water to which had been added minute quantities of formaldehyde. The samples were agitated, and the material settling out was sieved through fine mesh screens. Algal etc. samples were also examined by hand for species such as Podocerus which do not readily release their grip on the substrate. Immediately on return to the laboratory, the amphipods were picked out under a high power stereoscopic microscope and preserved in $70 \%$ alcohol. Prior to preservation, notes were made whenever possible on the 